\title{
Prediction of Tensile Strength and Elongation of High Alloy Steels during Solidification
}

\author{
Hideo MIZUKAMI, Yoshihisa SHIRAI and Akihiro YAMANAKA \\ Corporate Research \& Development Laboratories, Sumitomo Metal Industries, Ltd., 16-1 Sunayama, Kamisu, Ibaraki-pref \\ 314-0255 Japan.
}

(Received on January 12, 2006; accepted on March 10, 2006)

\begin{abstract}
Phase dependence of tensile strength of high alloy steel during solidification has been studied by a technique for high temperature tensile testing. The experimental technique enabled a sample to melt and solidify without a crucible, and the measurement of a minute load in a solidification temperature range became possible. A numerical model for the analysis of phase transformation during solidification was developed with the assumption that local equilibrium holds at liquid/solid interface or $\delta / \gamma$ phase interface.

The zero strength temperature was in agreement with zero ductility temperature, and both of these temperatures appeared at the fraction solid of 0.8 . Both the tensile strength and elongation of high alloy steel were dependent on the phase state but not on chromium and nickel contents. The tensile strength in (liquid $+\delta$ ), (liquid $+\gamma$ ), (liquid $+\delta+\gamma)$ and $(\delta+\gamma)$ coexisting state could be predicted using the experimental results. These estimated values are in good agreement with experimental results.
\end{abstract}

KEY WORDS: tensile strength; elongation; high alloy steel; solidification; transformation; solute redistribution.

\section{Introduction}

To optimize the casting conditions of high alloy steel products and improve the surface and internal quality of products, it is necessary to know the high temperature properties of steel which determine the deformation behavior of products. Many researchers ${ }^{1-14}$ ) have studied tensile strength and elongation which were high temperature properties of steel.

The solidification mode of high alloy steel changes depending on the chromium and nickel concentration during solidification, and the primary phase might become either $\delta$ or $\gamma$ phase in the same manner as carbon steel. Moreover, the $\delta / \gamma$ transformation occasionally occurs during solidification, and then the solidification sequence is finally completed. Though, in this way, it seems to be important to consider the phase change during solidification for understanding the deformation behavior of solidified shell. However there have been few studies on the relationship between phase and tensile strength of high alloy steel.

Therefore, in the present study, using a high temperature tensile test device where the measurement of a minute load is possible, the behavior of both tensile strength and elongation during and after solidification of high alloy steel were examined. Moreover, the application of predicted equations of tensile strength and elongation during solidification based on the measurement results concerning stainless steel, ${ }^{15)}$ carbon steels ${ }^{16), 17)}$ and high chromium steels ${ }^{18)}$ to high alloy steel was investigated and the generality of those equations in a wide range of concentration of chromium and nickel was examined.

\section{Experiment Procedures}

\subsection{Composition of Samples}

Chemical compositions of the steel samples are listed in Table 1. The $30 \mathrm{~kg}$ steel ingots were produced using the high purity electrolytic iron and the alloying elements made in a vacuum furnace, and then were hot forged at a temperature of $1373 \mathrm{~K}$ for in argon gas atmosphere to remove segregation in the sample. The sample was machined to the given size and shape from round bars of $2.5 \times 10^{-2} \mathrm{~m}$ in diameter.

\subsection{Experimental Apparatus}

Figure 1 shows a schematic diagram of the high temperature tensile test apparatus. The load cell is put in the vacuum vessel, and the atmosphere in the vessel was replaced by argon gas after evacuation with a diffusion pump to $1 \times 10^{-3} \mathrm{~Pa}$ before the experiment. The high temperature tensile test apparatus is composed of a high frequency induction coil, a loading cell, a two-color optical pyrometer and a high-speed video camera.

The sample size was $1 \times 10^{-2} \mathrm{~m}$ in diameter and $1 \times$ $10^{-1} \mathrm{~m}$ in length. Both the top and bottom part of the sam-

Table 1. Chemical composition of steel sample (mass\%).

\begin{tabular}{c|c|c|c|c|c|c|c}
\hline Sample & $\mathrm{Cr}$ & $\mathrm{Ni}$ & $\mathrm{C}$ & $\mathrm{Si}$ & $\mathrm{Mn}$ & $\mathrm{P}$ & $\mathrm{S}$ \\
\hline HA1 & 19.80 & 10.59 & 0.025 & 0.33 & 0.45 & 0.021 & 0.002 \\
\hline HA2 & 20.06 & 29.73 & 0.024 & 0.34 & 0.34 & 0.018 & 0.002 \\
\hline HA3 & 21.03 & 40.35 & 0.021 & 0.24 & 0.25 & 0.016 & 0.002 \\
\hline HA4 & 24.18 & 9.57 & 0.016 & 0.35 & 0.49 & 0.021 & 0.002 \\
\hline HA5 & 25.06 & 20.18 & 0.014 & 0.41 & 0.69 & 0.022 & 0.003 \\
\hline HA6 & 25.13 & 31.78 & 0.013 & 0.31 & 0.41 & 0.016 & 0.002 \\
\hline HA7 & 25.18 & 35.91 & 0.028 & 0.39 & 0.53 & 0.016 & 0.002 \\
\hline HA8 & 29.48 & 59.14 & 0.020 & 0.28 & 0.29 & 0.014 & 0.002 \\
\hline
\end{tabular}




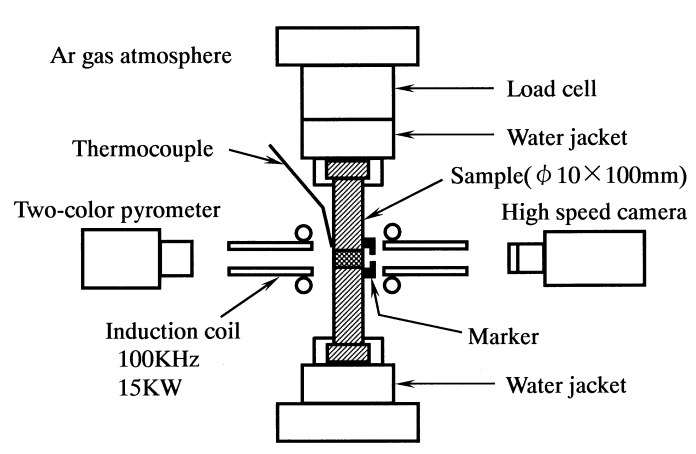

Fig. 1. Schematic diagram of experimental system of tensile strength during and after solidification.

ple were machined into the shape of a flange, and it improved the fixed position of the cylinders and the performance of the water-cooled jacket. Then the cooling condition at both the top and the bottom part of the sample was assumed to be equal, and the temperature distribution of the sample in the direction of length was also assumed to be evened. The center region of $5 \times 10^{-3} \mathrm{~m}$ in length of sample was melted by high frequency induction heating, and then the load was measured after reaching the prescribed conditions. The gravity force is not influenced in the measured load because the shape of molten zone of the sample is maintained by both the surface tension and the electromagnetic force. The temperature of molten zone was controlled by a R-type thermocouple of $1 \times 10^{-4} \mathrm{~m}$ in diameter welded to the sample surface at $5 \times 10^{-3} \mathrm{~m}$ from molten zone, using the regression line obtained from a preliminary experiment which had decided the relation between the temperature of molten zone and the controlled point.

The temperature of sample surface was measured with either a R-type thermocouple welded to the center of heating region below solidus temperature or a two-color optical pyrometer above solidus temperature. The temperature of center of sample was measured with a R-type thermocouple of which the tip was coated with almina cement and set at the center in length of sample through hole drilled from the top of sample. It was confirmed that the temperature of sample surface was agreement with that of center of sample.

The high frequency induction heating coil used in study was made from two copper coil-shaped rings separated vertically $5 \times 10^{-3} \mathrm{~m}$ from each other. Because the molten zone in the sample was able to be observed directly from the space between two coil-shaped rings of coil, a two-color optical pyrometer was used together with a R-type thermocouple. Moreover, cylindrical markers made of alumina of $1 \times 10^{-3} \mathrm{~m}$ in diameter were fixed to the surface on the upper and lower right side of the molten zone with alumina adhesive, and then the change in position of this marker was recorded with a high-speed video with a time resolution of $2.2 \times 10^{-4} \mathrm{~s}$ and space resolution of $2.0 \times 10^{-6} \mathrm{~m}$. From these experimental results of the displacement of solidifying region of the sample, the elongation of the sample was calculated during solidification.

The output signal of the load cell with a minimum detection of tensile strength of $0.01 \mathrm{MPa}$ was recorded in the data logger with a time resolution of $1 \times 10^{-6} \mathrm{~s}$. The data logger was synchronized with a high-speed video to start record at the same time.

\subsection{Control Conditions of High Temperature Tensile Test}

The sample was heated, melted and solidified sequentially according to the control conditions of high temperature tensile test. The temperature of molten zone was raised from room temperature to (solidus temperature -30) $\mathrm{K}$ and maintained at this temperature for $30 \mathrm{~s}$, and then the temperature was raised to (liquidus temperature-30) $\mathrm{K}$ again and maintained for $120 \mathrm{~s}$ to keep the steady state. Afterwards, the sample was cooled at a cooling rate of $0.17 \mathrm{~K} \mathrm{~s}^{-1}$ which corresponded to about one-quarter thickness of the continuously cast steel slabs as well as Shin et al. ${ }^{8)}$ Liquidus temperature $T_{\mathrm{L}}$ and solidus temperature $T_{\mathrm{S}}$ were obtained by the thermodynamics equilibrium calculation software. ${ }^{21)}$

The load zero control as control conditions of tensile test was adopted until becoming $T_{\mathrm{S}}$ at the temperature of molten zone, and then displacement was controlled over $T_{\mathrm{S}}$. Under these control conditions, the influence of the load addition by heat expansion of sample was ignored, and the deformation of sample by the compression of molten region was prevented. When the temperature of the molten zone reached at a preset temperature, the sample was pulled at a strain rate of $1 \times 10^{-2} \mathrm{~s}^{-1}$ and the load was measured.

\section{Analytical Method}

The relationship between tensile strength and phase state during solidification that was predicted by using solute redistribution model ${ }^{16)}$ was examined.

The solute redistribution model used in this analysis is based on the variable space network method constructed by Murray et al. ${ }^{19-21)}$ The characteristics of this method is able to specify the position $R$ at liquid $/ \delta$, liquid $/ \gamma$ and $\delta / \gamma$ interface. Therefore, the local equilibrium at the interface on phase transformation is possible to assume, and the solute redistribution model connected with the thermodynamics equilibrium calculation is able to be used. In the following, the analytical method in (liquid $+\delta+\gamma$ ) three-phase is shown as an example:

Diffusion equations

$$
\begin{aligned}
& \frac{\partial C_{i}^{\mathrm{L}}}{\partial t}=\left(\frac{\partial C_{i}^{\mathrm{L}}}{\partial x}\right) \frac{\partial x_{n}^{\mathrm{L}}}{\partial t}+D_{i}^{\mathrm{L}} \frac{\partial^{2} C_{i}^{\mathrm{L}}}{\partial x^{2}} \\
& \frac{\partial C_{i}^{\delta}}{\partial t}=\left(\frac{\partial C_{i}^{\delta}}{\partial x}\right) \frac{\partial x_{n}^{\delta}}{\partial t}+D_{i}^{\delta} \frac{\partial^{2} C_{i}^{\delta}}{\partial x^{2}} \\
& \frac{\partial C_{i}^{\gamma}}{\partial t}=\left(\frac{\partial C_{i}^{\gamma}}{\partial x}\right) \frac{\partial x_{n}^{\gamma}}{\partial t}+D_{i}^{\gamma} \frac{\partial^{2} C_{i}^{\gamma}}{\partial x^{2}} \\
& \frac{\partial x_{n}^{\delta}}{\partial t}=\left(\frac{x_{n}^{\delta}}{R}\right) \frac{\partial R^{\delta / \gamma}}{\partial t}: 0 \leqq x_{n}^{\delta}<R^{\delta / \gamma} \\
& \frac{\partial x_{n}^{\gamma}}{\partial t}=\left(\frac{x_{n}^{\gamma}-R^{\gamma / \mathrm{L}}}{R^{\gamma / \mathrm{L}}-R^{\delta / \gamma}}\right)\left(\frac{\partial R^{\gamma / \mathrm{L}}}{\partial t}-\frac{\partial R^{\delta / \gamma}}{\partial t}\right): \\
& R^{\delta / \gamma} \leqq x_{n}^{\gamma}<R^{\gamma / \mathrm{L}}
\end{aligned}
$$




$$
\frac{\partial x_{n}^{\mathrm{L}}}{\partial t}=\left(\frac{\lambda_{1} / 2-x_{n}^{\mathrm{L}}}{\lambda_{1} / 2-R^{\gamma / \mathrm{L}}}\right) \frac{\partial R^{\gamma / \mathrm{L}}}{\partial t}: \quad R^{\gamma / \mathrm{L}} \leqq x_{n}^{\mathrm{L}} \leqq \lambda_{1} / 2
$$

$\frac{\partial x_{n}^{\mathrm{L}}}{\partial t}, \frac{\partial x_{n}^{\delta}}{\partial t}, \frac{\partial x_{n}^{\gamma}}{\partial t}: \begin{aligned} & \text { velocity of grid } x_{n}^{L}, x_{n}^{\delta} \text { and } x_{n}^{\gamma} \text { of liq- } \\ & \text { uid, } \delta \text { and } \gamma \text { phase }\end{aligned}$ $\frac{\partial R^{\gamma / \mathrm{L}}}{\partial t}, \frac{\partial R^{\delta / \gamma}}{\partial t}: \begin{aligned} & \text { velocity of liquid } / \gamma, \text { and } \delta / \gamma \text { inter- } \\ & \text { face }\end{aligned}$ $\lambda_{1}$ : $\quad$ primary dendrite arm spacing

Boundary conditions

$$
\begin{gathered}
D_{i}^{\delta} \frac{\partial C_{i}^{\delta}}{\partial x}=0, \quad x=0 \\
D_{i}^{\mathrm{L}} \frac{\partial C_{i}^{\mathrm{L}}}{\partial x}=0, \quad x=\lambda_{1} / 2
\end{gathered}
$$

Mass balance at liquid $/ \gamma, \delta / \gamma$ interface

$$
\begin{gathered}
\frac{\partial R^{\delta / \gamma}}{\partial t}\left(C_{i}^{\delta}-C_{i}^{\gamma}\right)=D_{i}^{\delta} \frac{\partial C_{i}^{\delta}}{\partial x}-D_{i}^{\gamma} \frac{\partial C_{i}^{\gamma}}{\partial x} \\
\frac{\partial R^{\gamma / \mathrm{L}}}{\partial t}\left(C_{i}^{\gamma}-C_{i}^{\mathrm{L}}\right)=D_{i}^{\gamma} \frac{\partial C_{i}^{\gamma}}{\partial x}-D_{i}^{\mathrm{L}} \frac{\partial C_{i}^{\mathrm{L}}}{\partial x}
\end{gathered}
$$

Where, $C_{i}^{j}$ : concentration of element $i$ in $j$ phase (mass $\%$ ) ( $j=$ liquid, $\delta$ or $\gamma$ phase), $D_{i}^{j}$ : diffusion coefficient of element $i$ in $j$ phase $\left(\mathrm{m}^{2} \mathrm{~s}^{-1}\right), \mathrm{x}_{n}^{j}$ : position of grid $n$ in $j$ phase (m), $R^{\delta / \gamma}$ : position of $\delta / \gamma$ interface $(\mathrm{m}), R^{\gamma / \mathrm{L}}$ : position of liquid $/ \gamma$ interface (m) and $t:$ time (s).

The equations made a finite difference and then the numerical analysis was completed. The analytical methods concerning (liquid $+\delta)$, (liquid $+\gamma)$ and $(\delta+\gamma)$ two-phase are also similar.

Figure 2 shows the flow chart of this analytical model. After initial composition, start temperature, an analytical element size and a cooling rate are input, the diffusion equations of volume element in an analytical element are solved. First of all, whether the primary phase is $\delta$ phase or $\gamma$ phase is judged from the relation between solute concentration and temperature in each mesh in an analytical element. When the primary phase is $\gamma$ phase, the final phase is also $\gamma$ phase in this analytical range. When the primary phase is a $\delta$ phase, it is judged whether a $\gamma$ phase forms from the result of the thermodynamic equilibrium calculation during solidification. When the $\delta / \gamma$ transformation is caused during solidification, the (liquid $+\delta+\gamma$ ) three-phase becomes either the $(\delta+\gamma)$ two-phase or the $\gamma$ single phase at complete solidification. Temperature $T_{\text {emp }}$ is made to descend with a cooling rate $\dot{T}$ and time step $\Delta t$ until $T_{\text {emp }}$ reaches final temperature $T_{\text {emp,end }}$. Here, the final temperature $T_{\text {empend }}$ was $1400 \mathrm{~K}$ which was a lower bound of the experiment, and the liquidus temperature, the $\delta / \gamma$ transformation temperature and the solidus temperature were decided from the thermodynamic equilibrium calculation ${ }^{22)}$ considered to be solute redistribution.

The physical properties used by calculation are listed in

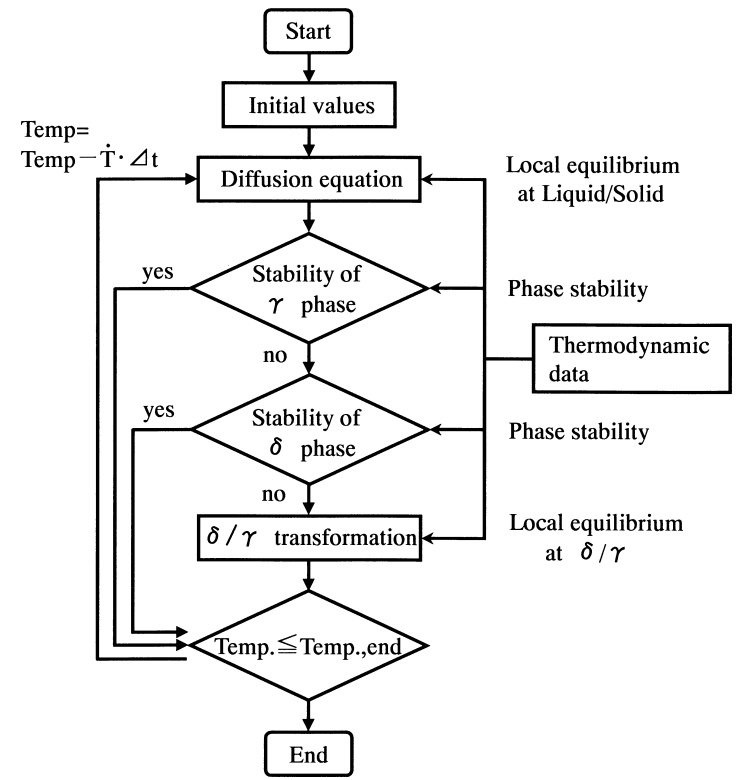

Fig. 2. Flow chart of calculation for the solute redistribution during and after solidification.

Table 2. Diffusion coefficient.

\begin{tabular}{c|c|c|c}
\hline Element & $\mathrm{D}^{\delta}, \mathrm{m}^{2} / \mathrm{s}^{23)}$ & $\mathrm{D}^{\gamma}, \mathrm{m}^{2} / \mathrm{s}^{23)}$ & $\mathrm{D}^{\mathrm{L}}, \mathrm{m}^{2} / \mathrm{s}^{24}$ \\
\hline $\mathrm{C}$ & $1.27 \times 10^{-6} \exp (-19450 / \mathrm{RT})$ & $7.61 \times 10^{-6} \exp (-32160 / \mathrm{RT})$ & $8.4 \times 10^{-7}$ \\
\hline $\mathrm{Si}$ & $8.0 \times 10^{-4} \exp (-59500 / \mathrm{RT})$ & $3.0 \times 10^{-5} \exp (-60100 / \mathrm{RT})$ & $5.1 \times 10^{-8}$ \\
\hline $\mathrm{Mn}$ & $7.6 \times 10^{-5} \exp (-53640 / \mathrm{RT})$ & $5.5 \times 10^{-6} \exp (-59600 / \mathrm{RT})$ & $4.4 \times 10^{-9}$ \\
\hline $\mathrm{P}$ & $2.9 \times 10^{-4} \exp (-55000 / \mathrm{RT})$ & $1.0 \times 10^{-6} \exp (-43700 / \mathrm{RT})$ & $1.4 \times 10^{-9}$ \\
\hline $\mathrm{S}$ & $4.56 \times 10^{-4} \exp (-51300 / \mathrm{RT})$ & $2.4 \times 10^{-4} \exp (-53400 / \mathrm{RT})$ & $4.3 \times 10^{-8}$ \\
\hline $\mathrm{Cr}$ & $2.3 \times 10^{-4} \exp (-57200 / \mathrm{RT})$ & $1.69 \times 10^{-5} \exp (-63200 / \mathrm{RT})$ & $4.8 \times 10^{-9}$ \\
\hline $\mathrm{Ni}$ & $2.4 \times 10^{-4} \exp (-57800 / \mathrm{RT})$ & $1.1 \times 10^{-5} \exp (-65200 / \mathrm{RT})$ & $4.9 \times 10^{-9}$ \\
\hline
\end{tabular}

Table 3. Calculation conditions.

\begin{tabular}{l|l}
\hline Parameter & Value \\
\hline Primary dendrite arm spacing, $\mu \mathrm{m}$ & 700 \\
\hline Number of segments & 300 \\
\hline Cooling rate, $\mathrm{Ks}^{-1}$ & 0.17 \\
\hline Position of initial interface, $\mu \mathrm{m}$ & 1.0 \\
\hline
\end{tabular}

Table 2 and the calculation conditions are listed in Table 3. The relationship between primary dendrite arm spacing and concentration of solute element of high alloy steel is not specified. It was assumed that the primary dendrite arm spacing was constant $700 \mu \mathrm{m}$ at one-quarter of slab thickness the same as previous reports. ${ }^{25,26)}$

\section{Analytical Results}

To evaluate the validity of the solute redistribution model, it is necessary to compare the calculated result with the measured result of either solute content in the plane which is perpendicular to primary dendrite $\operatorname{arm}^{27)}$ or amount of $\delta / \gamma$ transformation varying with temperature. However, it has not found for experimental result of high alloy steel by now.

Though it does not show the validity of the solute redistribution model, the relationship between fraction of solid and temperature which calculated using the thermodynamic equilibrium model or the Scheil mode was compared with the relationship by using the solute redistribution model.

Figure 3 shows the change of temperature with fraction of solid during solidification for sample HA1 by using the 


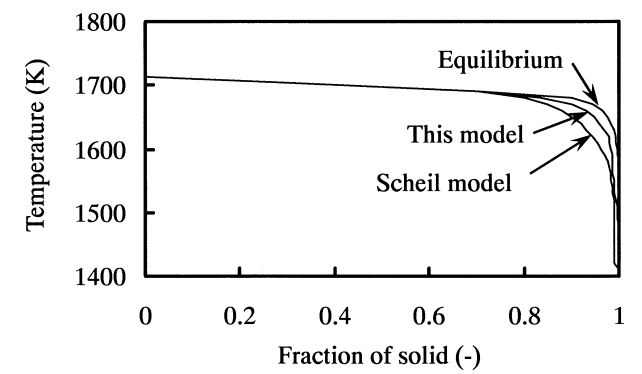

Fig. 3. Comparison of calculated relation between temperature and fraction of solid of this model with the equilibrium model and the Scheil model.

thermodynamic equilibrium model, the Scheil model and the solute redistribution model. Up to fraction of solid 0.8 , the predicted temperature by these models was almost agreement with each other. When the fraction of solid was about 0.8 or more, the difference between these predicted temperature occurred and the temperature at fraction of solid 1.0 became lower in the order of the thermodynamic equilibrium model, the solute redistribute model and the Scheil model.

The relationship between phase state and temperature during solidification is predicted according to the analytical model, and then the results are shown in Fig. 4.

Figure 4(a) shows the relationship between fraction of phase and temperature of sample HA1. The primary phase of this sample was a $\delta$ phase, and the (liquid $+\delta+\gamma$ ) threephase formed because of the appearance of $\gamma$ phase before complete solidification. The liquid phase disappeared with progress of solidification, and solidification was completed in the state of $(\delta+\gamma)$ coexisting phase.

Figures 4(b) and 4(c) show the phase change behavior of sample HA2 and HA3, respectively. The primary phase was a $\gamma$ phase and the $\gamma$ single phase formed when the solidification was completed without the transformation.

Figure 4(d) shows the relationship between fraction of phase and temperature of sample HA4. The primary phase of this sample was a $\delta$ phase and a $\gamma$ phase precipitated just above solidus temperature and the (liquid $+\gamma+\delta$ ) coexisting phase formed in the mushy zone. After complete solidification, the $(\delta+\gamma)$ coexisting phase was formed.

The phase change of sample HA5 is shown in Fig. 4(e). The primary phase was a $\gamma$ phase and the $\delta$ phase precipitated during solidification and the (liquid $+\gamma+\delta$ ) coexisting phase formed. At the solidus temperature, the $(\delta+\gamma)$ coexisting phase formed of which the fraction of $\delta$ phase was small. Below the solidus temperature, the $\delta$ phase disappeared and the $\gamma$ single phase formed.

Figure 4(f) shows the change of fraction of phase with temperature of sample HA6. The $\gamma$ phase was solidified as a primary phase and the $\gamma$ phase formed when the solidification was completed without the transformation. The $\delta$ phase precipitated in the $\gamma$ phase and the $(\delta+\gamma)$ coexisting phase formed.

Figures $4(\mathrm{~g})$ and $4(\mathrm{~h})$ show the phase change behavior of sample HA7 and HA8, respectively. The solidification mode of these samples was the same as sample HA6.

It is thought that tensile strength of steel products during solidification depends on the type of primary phase during solidification.
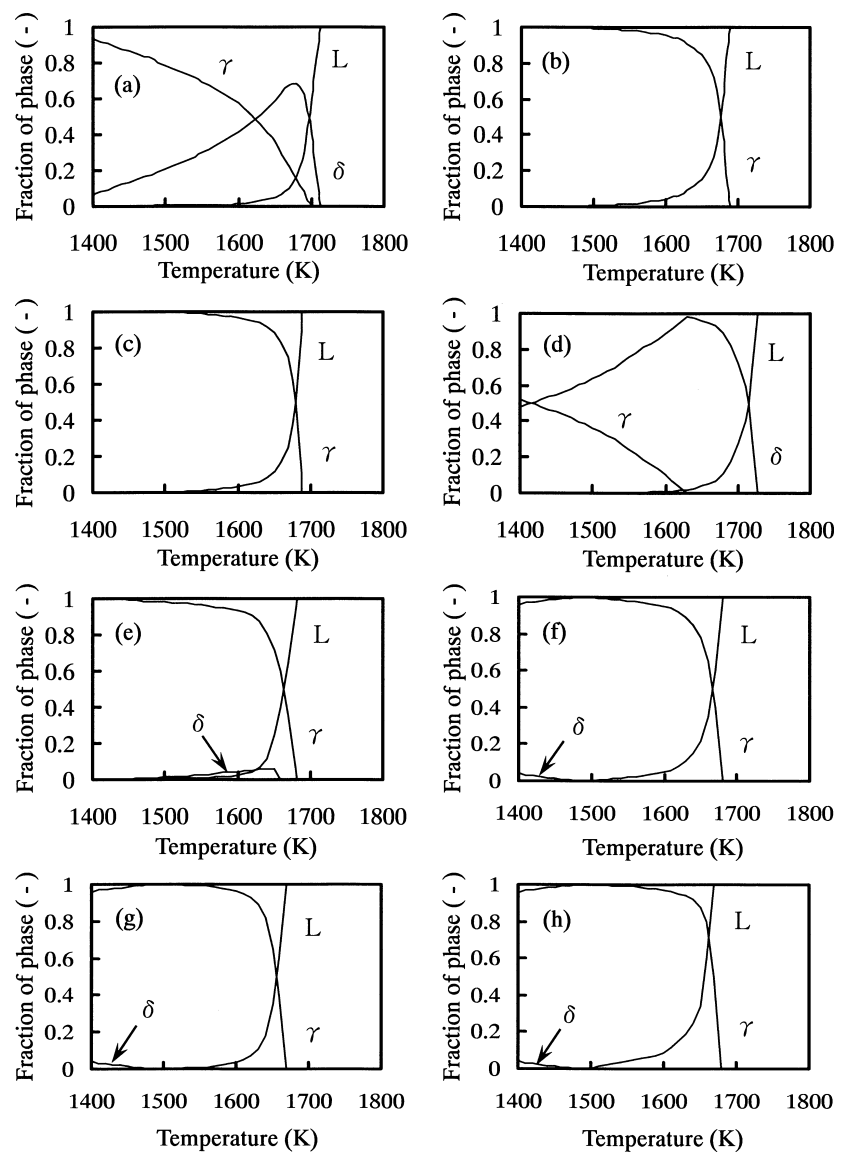

Fig. 4. Calculated results for the relationship between fraction of phase and temperature. (a) Sample HA1, (b) HA2, (c) HA3, (d) HA4, (e) HA5, (f) HA6, (g) HA7 and (h) HA8.

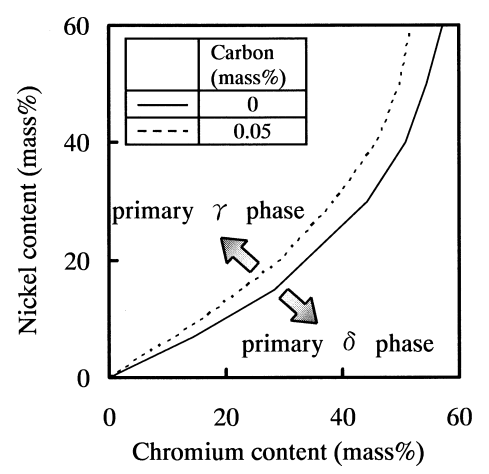

Fig. 5. Effect of chromium and nickel content on primary phase during solidification.

The type of primary phase which is predicted using thermodynamic calculation is arranged with the chromium and nickel content varying with carbon content, and the result is shown in Fig. 5. When the nickel content was low and the chromium content was high, the primary phase was a $\delta$ phase in the range of this experiment. When the nickel content was high and the chromium content was low, the primary phase was a $\gamma$ phase.

\section{Experimental Results}

Figure 6 shows the experimental results of tensile strength during solidification. The predicted result of tensile strength, which is shown by the solid line, is described later. 

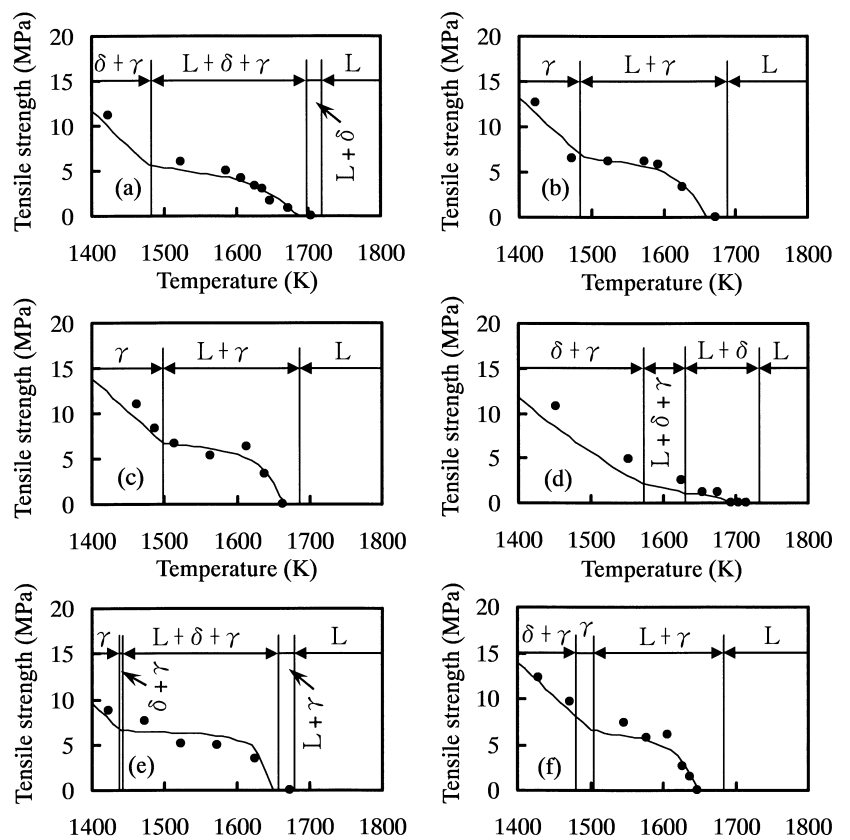

Temperature (K)
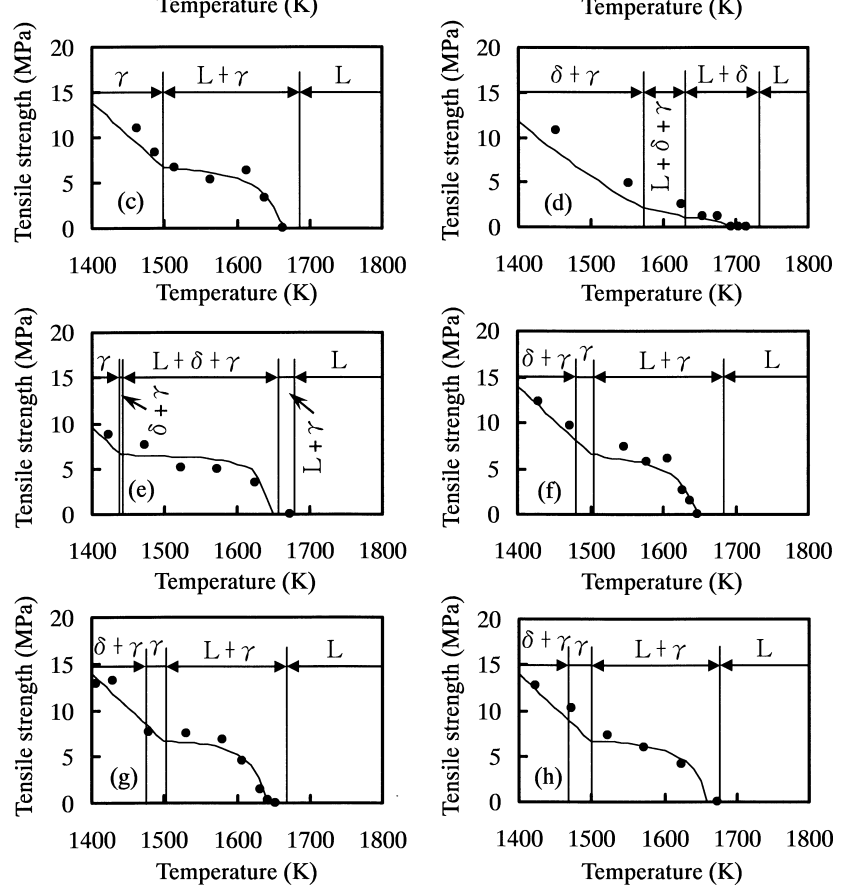

Fig. 6. Relationship between tensile strength and temperature during and after solidification. Filed circles represent the experimental results and solid line represents the calculated results, respectively. (a) Sample HA1, (b) HA2, (c) HA3, (d) HA4, (e) HA5, (f) HA6, (g) HA7 and (h) HA8.

Figure 6(a) shows the relationship between tensile strength and temperature of sample HA1. The tensile strength appeared in the liquid and solid coexistence region and increased with decreasing temperature. After solidification, the tensile strength was large in the $(\delta+\gamma)$ coexisting phase.

Figures 6(b) and 6(c) show the change of tensile strength with temperature of sample HA2 and HA3, respectively. The tensile strength appeared in the liquid and solid coexistence region and reached the value of about $6 \mathrm{MPa}$. After complete solidification, a $\gamma$ phase formed and the tensile strength increased with decreasing temperature linearly.

Figure 6(d) shows the relationship between tensile strength and temperature of sample HA4. The primary phase of this sample was a $\delta$ phase and the solidification mode was the same as sample HA1. The tensile strength appeared during solidification and did not increase very much during solidification. Above the solidus temperature, a $\gamma$ phase precipitated and the tensile strength increased with decreasing temperature during and after solidification.

The experimental results of tensile strength for sample HA5 are shown in Fig. 6(e). The tensile strength appeared in the (liquid $+\delta+\gamma$ ) coexisting phase and increased with decreasing temperature slightly.

Figures 6(f)-6(h) show the change of tensile strength with temperature of sample HA6, HA7 and HA8, respectively. The solidification mode of these samples was the

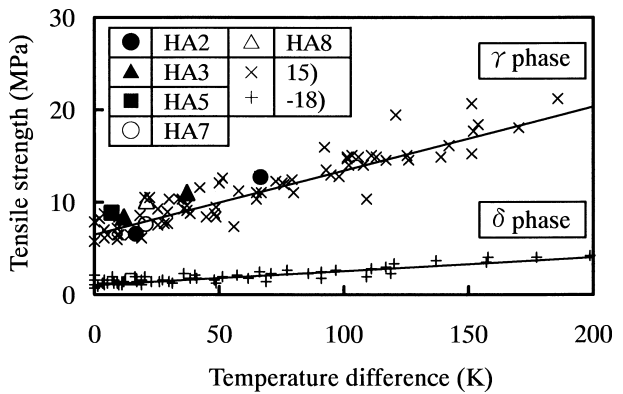

Fig. 7. Relationship between tensile strength and temperature difference after solidification for this study and previous studies. $^{15-18)}$

same. The tensile strength appeared in the (liquid $+\gamma)$ coexisting phase and increased with decreasing temperature during solidification. After complete solidification, the $\gamma$ single phase formed and then the $\delta$ phase precipitated in the $\gamma$ phase. Tensile strength increased with decreasing temperature after solidification.

From the experimental results, it is clarified that the tensile strength deeply relates to the phase transformation behavior.

\section{Discussions}

\subsection{Phase Dependency of Tensile Strength after Solid- ification}

The authors have measured the tensile strength of stainless steels, ${ }^{15)}$ carbon steels ${ }^{16,17)}$ and high chromium steels, ${ }^{18)}$ and then have experimentally shown that the tensile strength of $\delta$ single phase and $\gamma$ single phase could be arranged by the temperatures difference based on the temperature of transformation start and showed the equation of prediction of tensile strength after solidification as follows:

$$
\begin{gathered}
\sigma_{\delta}=0.015 \times\left(T_{\delta},_{\text {start }}-T\right)+12 . \\
\sigma_{\gamma}=0.073 \times\left(T_{\gamma} \text {,start }-T\right)+6.6
\end{gathered}
$$

Where, $\sigma_{j}$ : tensile strength of $j$ phase $(\mathrm{MPa})(j=\delta$ or $\gamma$ phase), $T_{j \text {,start }}$ : temperature of transformation start of $j$ phase $(\mathrm{K})$ and $T$ : temperature $(\mathrm{K})$.

In this study, the applicability of these predicted equations to the high alloy steel was examined.

Figure 7 shows the relationship between tensile strength and temperature difference after solidification. The plots were the experimental results for sample HA2, HA3, HA5, HA7 and HA8 which formed $\gamma$ single phase after solidification. There was no plot for $\delta$ single phase after solidification in this study. The solid line shows the predicted Eqs. (11) and (12). The temperatures difference means the difference between phase transformation start temperature and experimental temperature. As the experimental results for $\gamma$ phase are almost in good agreement with the predicted line, it is thought that the predicted equations can be adapted to the high alloy steels.

The difference between $\delta$ phase and $\gamma$ phase is mainly crystal structure, and the crystal structure of $\delta$ phase is body-centered cubic lattice and that of $\gamma$ phase is face-centered cubic lattice. The number of slip plane of body-centered cubic lattice is more than that of face-centered cubic 
lattice. Therefore, it seems that the $\delta$ phase is deformed more easily than the $\gamma$ phase.

However, the effects of recovery, recrystallization and energy of stacking fault on the difference of tensile strength between $\delta$ phase and $\gamma$ phase during solidification were not found.

\subsection{Tensile Strength and Elongation during Solidifica- tion}

It is necessary to clarify the behavior of tensile strength and elongation during solidification, because it is thought that surface and internal cracking in steel products relate to the stress in solidified shell.

The predicted equation of tensile strength and elongation during solidification has been derived from the experiment results for carbon steels as follows:

$$
\begin{array}{ll}
\sigma_{\delta}^{\mathrm{L} / \mathrm{S}}=6.0 \times\left(f_{\mathrm{s}}-0.8\right) \times f_{\delta}, & 0.8 \leq f_{\mathrm{s}} \leq 1.0 \ldots \\
\sigma_{\delta}^{\mathrm{L} / \mathrm{S}}=33.5 \times\left(f_{\mathrm{s}}-0.8\right) \times f_{\gamma}, & 0.8 \leq f_{\mathrm{s}} \leq 1.0 \ldots \\
\sigma_{\delta}^{\mathrm{L} / \mathrm{S}}=6.5 \times\left(f_{\mathrm{s}}-0.8\right) \times f_{\delta}, & 0.8 \leq f_{\mathrm{s}} \leq 1.0 \ldots \\
\sigma_{\delta}^{\mathrm{L} / \mathrm{S}}=6.5 \times\left(f_{\mathrm{s}}-0.8\right) \times f_{\gamma}, & 0.8 \leq f_{\mathrm{s}} \leq 1.0 \ldots
\end{array}
$$

Where, $\sigma_{j}^{\mathrm{L} / \mathrm{s}}$ : tensile strength of $j$ phase during solidification (MPa) $\left(j=\delta\right.$ or $\gamma$ phase), $\varepsilon_{j}^{\mathrm{L} / \mathrm{s}}$ : elongation of $j$ phase during solidification $(\%), f_{j}$ : mass fraction of $j$ phase $(-)$ and $f_{\mathrm{s}}$ : fraction solid $(-)$, respectively.

In this study, it was examined whether these predicted equations can be adapted to the high alloy steels.

Figures 8(a) and 8(b) shows the relationship between tensile strength, elongation and fraction of solid during solidification. The fraction of solid in these figures is obtained by the calculation. The tensile strength and elongation of $\delta$ phase were the measured value of sample HA4 and that of $\gamma$ phase were the value of sample HA2, HA3, HA6, HA7 and HA8.

Figure 8(a) shows the change of tensile strength during solidification with fraction of solid. The solid line is the predicted value by using Eqs. (13) and (14). As the mea-
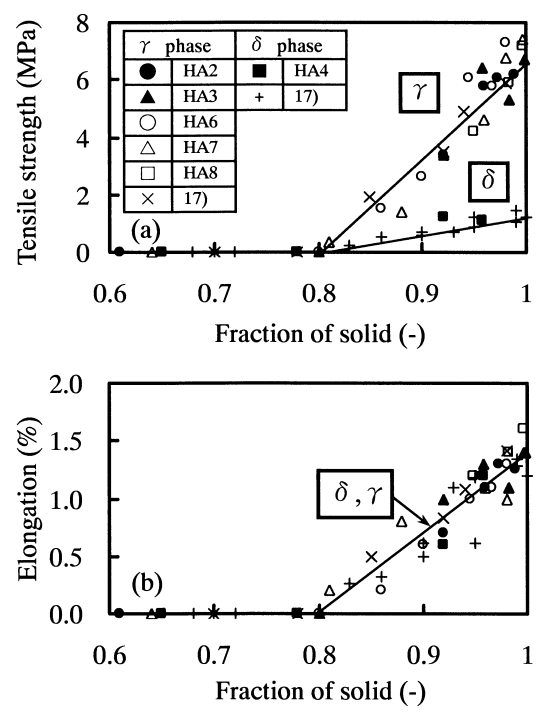

Fig. 8. Relationship between (a) tensile strength and (b) elongation and fraction of solid during solidification for this study and previous studies. ${ }^{17)}$ sured value of tensile strength for $\delta$ phase and $\gamma$ phase are in good agreement with the predicted value, the predicted equations are seemed to apply high alloy steel. The tensile strength appeared at fraction of solid 0.8 the same as carbon steel and stainless steel. After the appearance of tensile strength, the tensile strength of both $\delta$ phase and $\gamma$ phase increased with increasing fraction of solid. The tensile strength of $\gamma$ phase was larger than that of $\delta$ phase.

Figure $8(\mathrm{~b})$ shows the relationship between elongation and fraction of solid. The solid line is the calculated result by Eqs. (15) and (16). The elongation of high alloy steel increased with increasing fraction of solid the same as carbon steel. As the measured values of elongation for high alloy steel are in good agreement with the predicted value, these equations is seemed to apply to the high alloy steel.

It seems that the dendrites begin to combine mutually at the fraction solid of $0.8^{32}$ because the tensile strength does not appear until the fraction solid of 0.8 in this experimental result, and the tensile strength also increases so that the combined region of dendrites may increase with increasing the fraction solid after dendrites combine mutually. Though the tensile strength increased as the fraction solid increased for both the $\delta$ phase and $\gamma$ phase linearly, the tensile strength changed with the phase state. The tensile strength of $\gamma$ phase was larger than that of $\delta$ phase when the solidification was completed.

However, the phase dependency observed for the tensile strength was not allowed by the elongation. Schmidtmann et $a l^{4-7)}$ reported that the zero ductility temperature was different from the zero strength temperature, because a minute elongation measured by a reduction area R.A. was not able to be evaluated.

\subsection{Prediction of Tensile Strength during and after Solidification}

Figures 7 and 8(a) showed that the tensile strength of $\delta$ phase and $\gamma$ phase of steel was able to be predicted after and during solidification, respectively.

In the following, the tensile strength in $(\delta+\gamma)$ coexisting phase was predicted by using the rule of additivity, ${ }^{28)}$ and the validity was examined by comparing with experimental results for high alloy steel. Depending on the rule of additivity, the tensile strength in $(\delta+\gamma)$ coexisting phase can be shown by the next expression as first approximation:

$$
\sigma_{(\delta+\gamma)}=\sigma_{\delta} \times f_{\delta}+\sigma_{\gamma} \times f_{\gamma}
$$

Where, $\sigma_{j}$ : tensile strength of $j$ phase $(\mathrm{MPa})(j=\delta+\gamma, \delta$ or $\gamma$ phase) and $f_{j}$ : mass fraction of $j$ phase $(-)$.

The tensile strength of $\delta$ single phase and $\gamma$ single phase were used by the relation shown in Figs. 7 and 8(a), and the mass fraction of $\delta$ phase and $\gamma$ phase were used by the relation shown in Fig. 4, respectively. The tensile strength of (liquid $+\delta+\gamma$ ) three-phase can be shown by the Eq. (17) because the tensile strength of liquid phase is zero.

The above equation was applied to sample HA1-HA8, and the measured value was compared with the predicted value, and then the validity of prediction by the rule of additivity was examined.

The predicted results of sample HA1-HA8 are shown in Figs. 6(a)-6(h) by the solid line, respectively. As the predicted value of tensile strength was in good agreement with 
the measured value, it seems that the tensile strength of $\gamma$ phase and $(\delta+\gamma)$ coexisting phase during and after solidification can be predicted by this prediction method.

\section{Conclusions}

The tensile strength and the elongation of high alloy steel was measured with a high temperature tensile test device during and after solidification. From the result of comparison of relationship between tensile strength and elongation, and phase state, the following conclusions were obtained.

(1) The tensile strength during and after solidification changed depending on the phase state.

(2) The predicted equations of tensile strength and elongation during and after solidification derived from the experimental results of carbon steel and stainless steel were able to apply to high alloy steel.

(3) The zero strength temperature was the same as the zero ductility temperature and this temperature corresponded to the fraction solid of 0.8 .

(4) The tensile strength and elongation during solidification was able to show with the equations as a function of fraction solid and fraction of phase. The tensile strength after solidification was able to show with the equations as a function of the temperature difference. The tensile strength of $(\delta+\gamma)$ coexisting phase during and after solidification was able to show with the equation by additivity rule as a first approximation.

\section{REFERENCES}

1) W. T. Lankford, Jr.: Metall. Trans., 3 (1972), 1331

2) H. Fuji, M. Oda, T. Ohashi, K. Kawamura and K. Asano: Tetsu-toHagané, 64 (1978), 2148.

3) H. Suzuki, S. Nishimura and S. Yamaguchi: Tetsu-to-Hagané, 65 (1979), 2038

4) E. Schmidtmann and L. Pleugel: Arch. Eisenhüttenwes., 51 (1980), 49.

5) E. Schmidtmann and L. Pleugel: Arch. Eisenhüttenwes., 51 (1980), 55.
6) E. Schmidtmann and F. Rakoski: Arch. Eisenhüttenwes., 54 (1983), 357.

7) E. Schmidtmann and F. Rakoski: Arch. Eisenhüttenwes., 54 (1983), 363.

8) G. Shin, T. Kajitani, T. Suzuki and T. Umeda: Tetsu-to-Hagané, 78 (1992), 587.

9) H. Hiebler and M. Wolf: CAMP-ISIJ, 6 (1993), 1132.

10) M. Hojo, I. Suichi and S.Tanaka: CAMP-ISIJ, 6 (1993), 1134.

11) P. Deprez, J. P. Bricout and J. Oudin: Mater. Sci. Eng. A, $\mathbf{A 1 6 8}$ (1994), 17.

12) T. Revaux, P. Deprez, J. Bricout and J. Oudin: ISIJ Int., 34 (1994), 528.

13) H. Mizukami, K. Murakami and Y. Kitagawa: Tetsu-to-Hagané, 81 (1995), 792.

14) T. Nakagawa, T. Umeda, J. Murata, Y. Kamimura and N. Niwa: ISIJ Int., 35 (1995), 723.

15) H. Mizukami, K. Nakajima, M. Kawamoto, T. Watanabe and T. Umeda: Tetsu-to-Hagané, 84 (1998), 417.

16) H. Mizukami, S. Hiraki, M. Kawamoto and T. Watanabe: Tetsu-toHagané, 84 (1998), 763.

17) H. Mizukami, A. Yamanaka and T. Watanabe: ISIJ Int., 42 (2002), 964.

18) H. Mizukami, A. Yamanaka and T. Watanabe: Tetsu-to-Hagané, 85 (1999), 592.

19) W. D. Murray and F. Landis: Trans. ASME, 81 (1959), 106.

20) J. O. Andersson, L. Hoglund, B. Jonsson and J. Ågren: Fundamentals and Applications of Ternary Diffusion, ed. by G. R. Purdy, Pergamon Press, New York, (1990), 153.

21) S. Crusius, G. Inden, U. Knoop, L. Hoglund and J. Ȧgren: Z. Metallkd., 83 (1992), 9.

22) B. Jansson, M. Schalin, M. Selleby and B. Sundman: Computer Software in Chemical and Extractive Metallurgy, ed. by C. W. Bale and G. A. Irons, The Met. Soc. of CIM, Quebec (1993), 57.

23) Y. Ueshima, S. Mizoguchi, T. Matumiya and H. Kajioka: Metall. Trans. B, 17B (1986), 845

24) Handbook of Physico-chemical Properties at High Temperature, ISIJ, Tokyo, (1988), 181

25) T. Watanabe: Doctor Thesis, Tohoku Univ., Sendai, Japan, (1988), 60

26) G. Shin, T. Suzuki and T. Umeda: Tetsu-to-Hagané, 78 (1992), 275.

27) T. Umeda, J. Matsuyama, H. Murayama and M. Sugiyama: Tetsu-toHagané, 63 (1977), 441.

28) Z. Fan, P. Tsakiropoulos, P. A. Smith and A. P. Miodownik: Philos Mag. A, 67 (1993), 515. 